
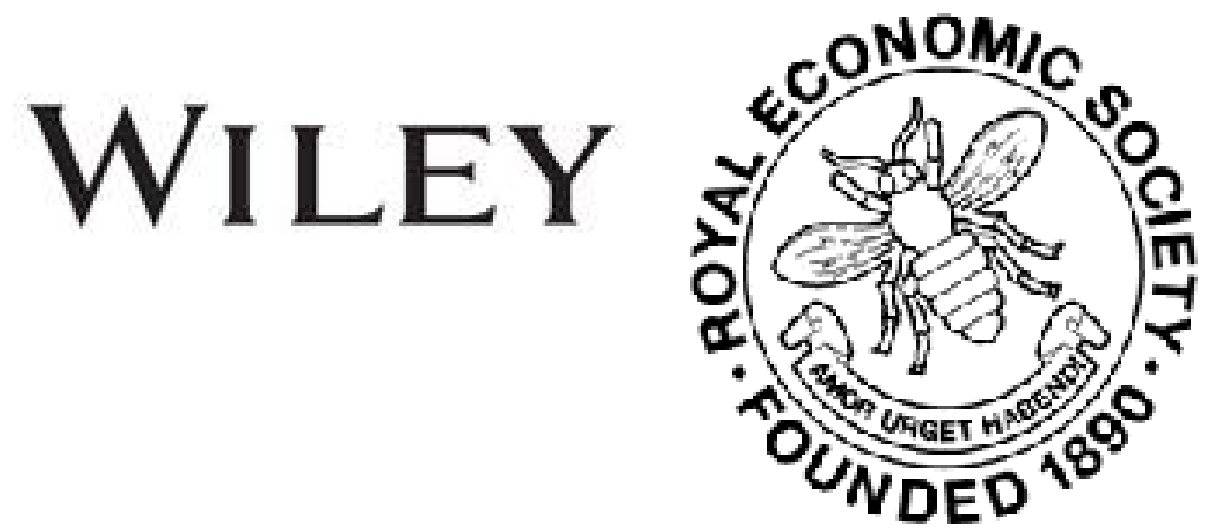

\title{
Poor Law Statistics
}

Author(s): Charles Booth

Source: The Economic Journal, Vol. 6, No. 21 (Mar., 1896), pp. 70-74

Published by: Wiley on behalf of the Royal Economic Society

Stable URL: http://www.jstor.org/stable/2956767

Accessed: 26-06-2016 20:34 UTC

Your use of the JSTOR archive indicates your acceptance of the Terms \& Conditions of Use, available at

http://about.jstor.org/terms

JSTOR is a not-for-profit service that helps scholars, researchers, and students discover, use, and build upon a wide range of content in a trusted digital archive. We use information technology and tools to increase productivity and facilitate new forms of scholarship. For more information about JSTOR, please contact support@jstor.org.

Wiley, Royal Economic Society are collaborating with JSTOR to digitize, preserve and extend access to The Economic Journal 


\section{POOR LAW STATISTICS.}

When in September, 1894, the Economic Journal published a criticism by Mr. Loch of my book on the Condition of the Aged Poor, I hoped within a short time to publish a second volume on the same subject, and thought that I could in that way best make such reply as was needed. The writing of this volume has been delayed, and Mr. Loch's criticisms have been followed by those of Mr. G. Udny Yule in the last number of the Journal. For any further exposition of my own views I should be content to wait, but so far as some statements in the book referred to may perhaps be accounted misleading, it is only right that I should either withdraw them or explain the sense in which I wish them to be understood.

Into Mr. Loch's treatment of my use of the figures in Mr. Ritchie's return I cannot go in detail here without occupying too much space. As regards the London figures of this return, I have always admitted inaccuracy. I corrected such errors as I could detect, but inaccuracy remained; not enough I think to invalidate the general conclusions, but sufficient to make it necessary to treat the results for London separately and with special caution. This I think I did. On the other hand, Mr. Loch admits that ' For the country, London excepted, the return may be taken as fairly accurate.'

I therefore pass to his criticisms on the 'Individual Comparisons,' and here meet Mr. Yule as well as Mr. Loch. I will first state what is attempted in these comparisons. In them the whole of the unions in England and Wales are divided into twenty groups, the lines of division being according to industrial character with some subdivisions according to density of population-the idea of this method of grouping being that wherever the population is on the whole similarly employed, and similarly conditioned as to sparseness or density, the unions might be compared in order to show what was the effect of varying systems of administration on 
pauperism. In laying these comparisons before my readers I admitted the necessity of more local knowledge ' to tread safely,' and that the 'results attained were chiefly negative'; but I did draw certain conclusions, and it is some of these conclusions that are attacked. Mr. Loch does not deny that the figures given do little to account for the wide differences in extent of pauperism shown, but claims that more information is required-first as to proportionate ages of each population, and second as to the history of the administration in each case; and on these grounds denies that my contention, that differences in principles of administration have little or no general effect, is tenable. Mr. Yule goes further, and argues that my contention can be disproved from my own figures. Finally, Mr. Loch regrets that statistical tables so elaborate and yet so incorrect in their conclusions should have been published by me, while Mr. Yule states that his conclusions are strongly at variance with mine, and compel him severely to criticise my methods.

The real question at issue is the influence on pauperism of the giving or withholding of out-relief. I found, or thought I found, that the degree of pauperism depended mainly on other considerations. I did not find much which suggested the influence of the form of administration on pauperism, but a good deal to show the influence on administration of the different shapes which pauperism assumes, due to density or sparseness of population, to the presence of many old people, to geographical or industrial characteristics, or to prosperity or the reverse as connected with increase or decrease of population; and I came to the conclusion that good results follow wherever an appropriate and well-considered policy is acted upon, whatever the policy may be. These conclusions I still believe to be borne out by all the available evidence. But I must in fairness say that the sentence in my book to which Mr. Yule's note mainly refers is in some degree misleading. I stated, as a deduction from the comparisons referred to, that 'the proportion of relief given out of doors bears no general relation to the total percentage of pauperism.' It is, however, quite true, as Mr. Yule contends, that on the average there is least pauperism where out-relief bears the smallest proportion to the total relief given, and it is true also that this is so whether the year's count or the day's count be taken. I cannot deny that an average comparison of this kind constitutes a 'general relation.' What I ought to have said was that a greater or less degree of pauperism was not coincident in any regular way with the degree of out-relief given, so as to show a persistent 
connection; and I regret that the words I used were open to misconception. What I mean by the failure to show any persistent connection, in spite of the averages on which $\mathrm{Mr}$. Yule relies, may be explained by the annexed diagram. For this purpose I will take the first group, consisting of fifty agricultural unions. with sparse population. The unions are arranged in order of degree of pauperism (on the twelve months' count), and the 'pauperism? line on the diagram indicates the fall from 12.7 per cent. at Stockbridge in Hants to 1.3 per cent. at Brixworth in Northampton. The 'out-relief' line which crosses the other one represents the proportion which the amount paid in out-relief bears to that paid for in and out together in each of these unions. On the whole we find an average of $7 \cdot 62$ per cent. pauperism in the first twentyfive unions with $68^{\circ} 4$ per cent. average proportion paid in out-relief, whereas with the second twenty-five unions the average proportion paid in out-relief is 66.7 per cent. and the average of pauperism only 3.13 per cent., proving it is true that in these unions on the average the smaller proportion paid in out-relief does go with the lowest rate of pauperism; yet leaving me I think fully justified in saying that there is no general relation between the two curves. Of the fifty unions about ten take their places in accordance with the out-relief line, the others seem to have no connection with it. The slight difference which the averages show (between 68.4 per cent. and 66.7 per cent.) is indeed entirely due to Brixworth; omit Brixworth (always an exception in matters of Poor Law administration) from the account, and the average proportion of out-relief is $68 \cdot 4$ per cent. in both divisions alike, although the difference in degree of pauperism is still as $7 \cdot 62$ to $3 \cdot 20$ !

Each of the twenty groups into which the whole number of unions are divided presents a result more or less similar to that shown on this diagram. The difference in the average percentage of pauperism in the two halves is always marked, whereas that of the amount paid in out-relief is usually very slight, and in three of the groups the ordinary rule is reversed, and we find a greater average of out-relief coincident with a smaller average of pauperism.

Mr. Loch's contention that I have not sufficiently isolated the influence of out-relief is perfectly true, and it is also true that other unconsidered canses may explain the irregularity of the upper curve, but if the checking or refusal of out-relief had so specific an effect as has been supposed, I hardly think it could be so completely overlaid. 
50 A GRIC U LTUF AVERAGE OUTRELIEF ( 25 UNIONS) $68.4 \%$

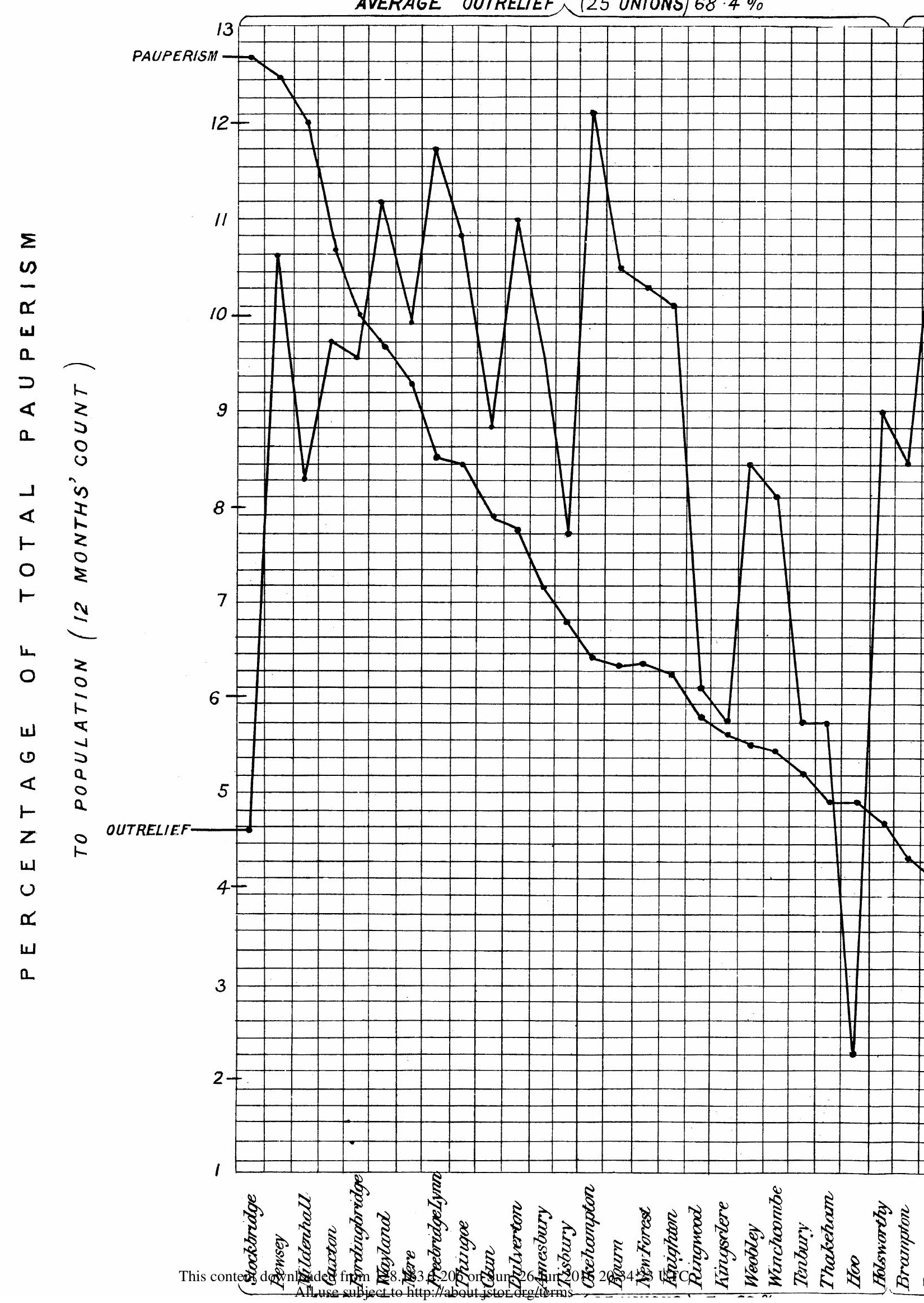


LTURAL UNIONS.

AVERAGE OUTRELIEF ( 25 UNIONS) $66.7 \%$

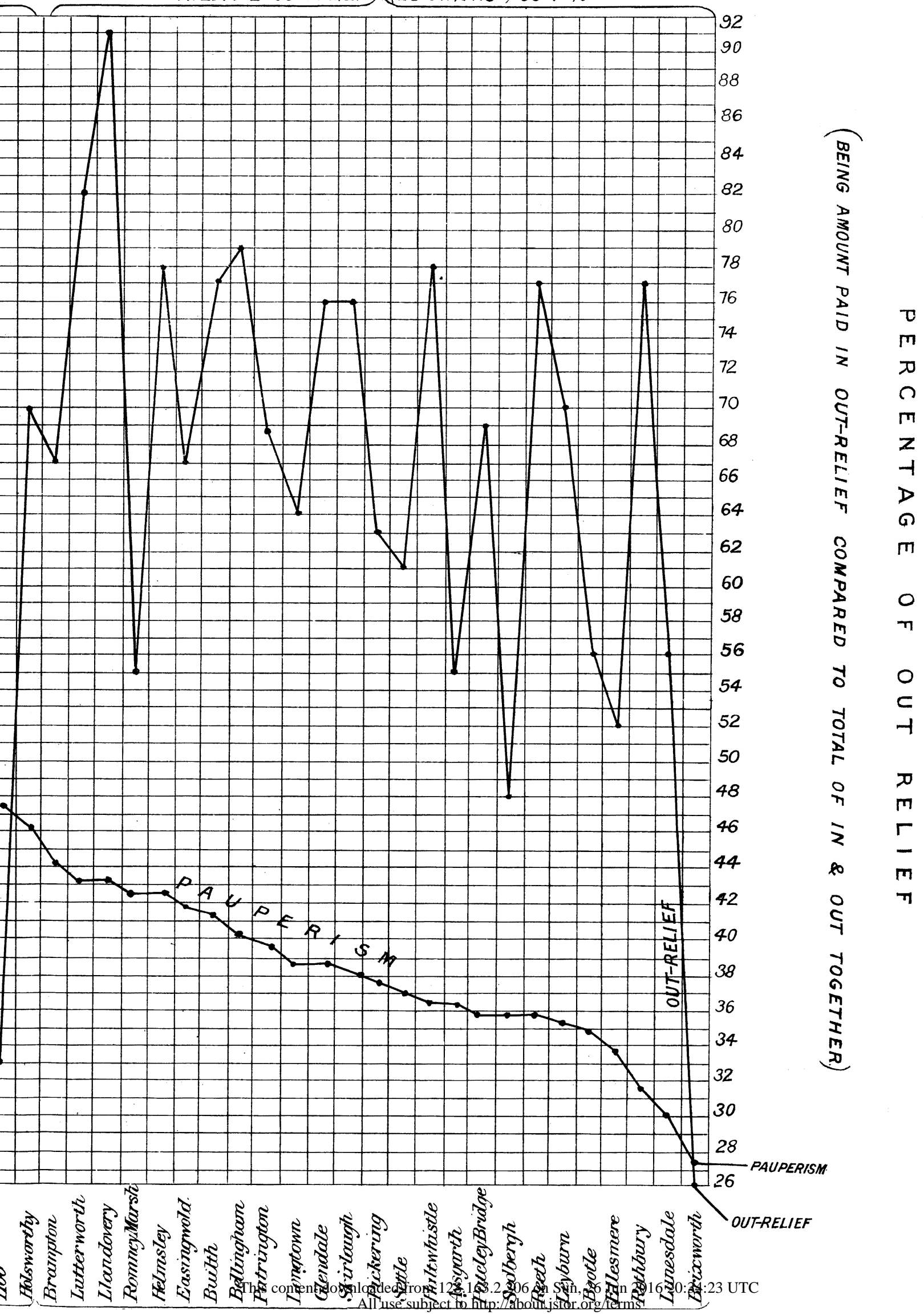




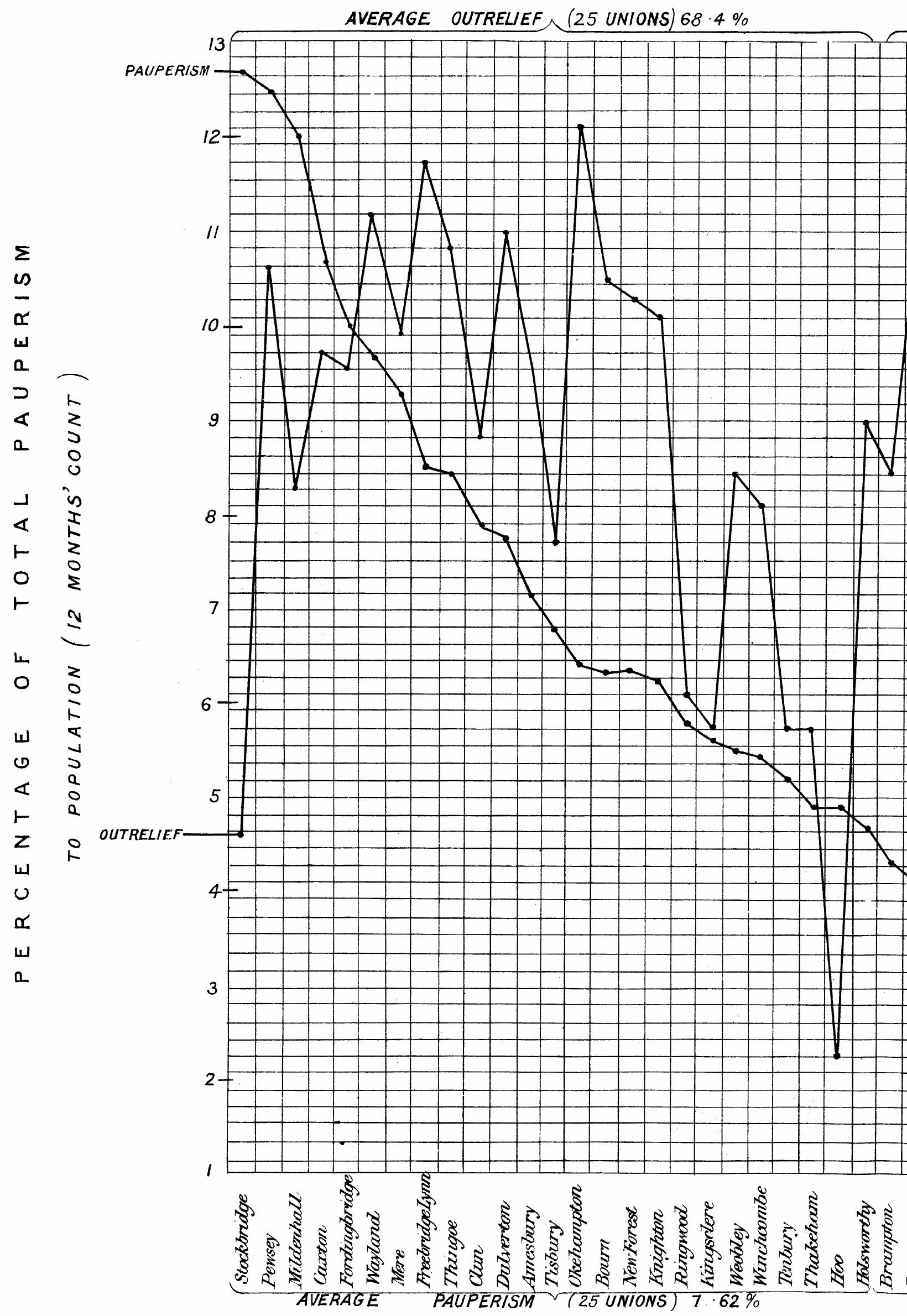


AVERAGE OUTRELIEF N (25 UNIONS) $66.7 \%$

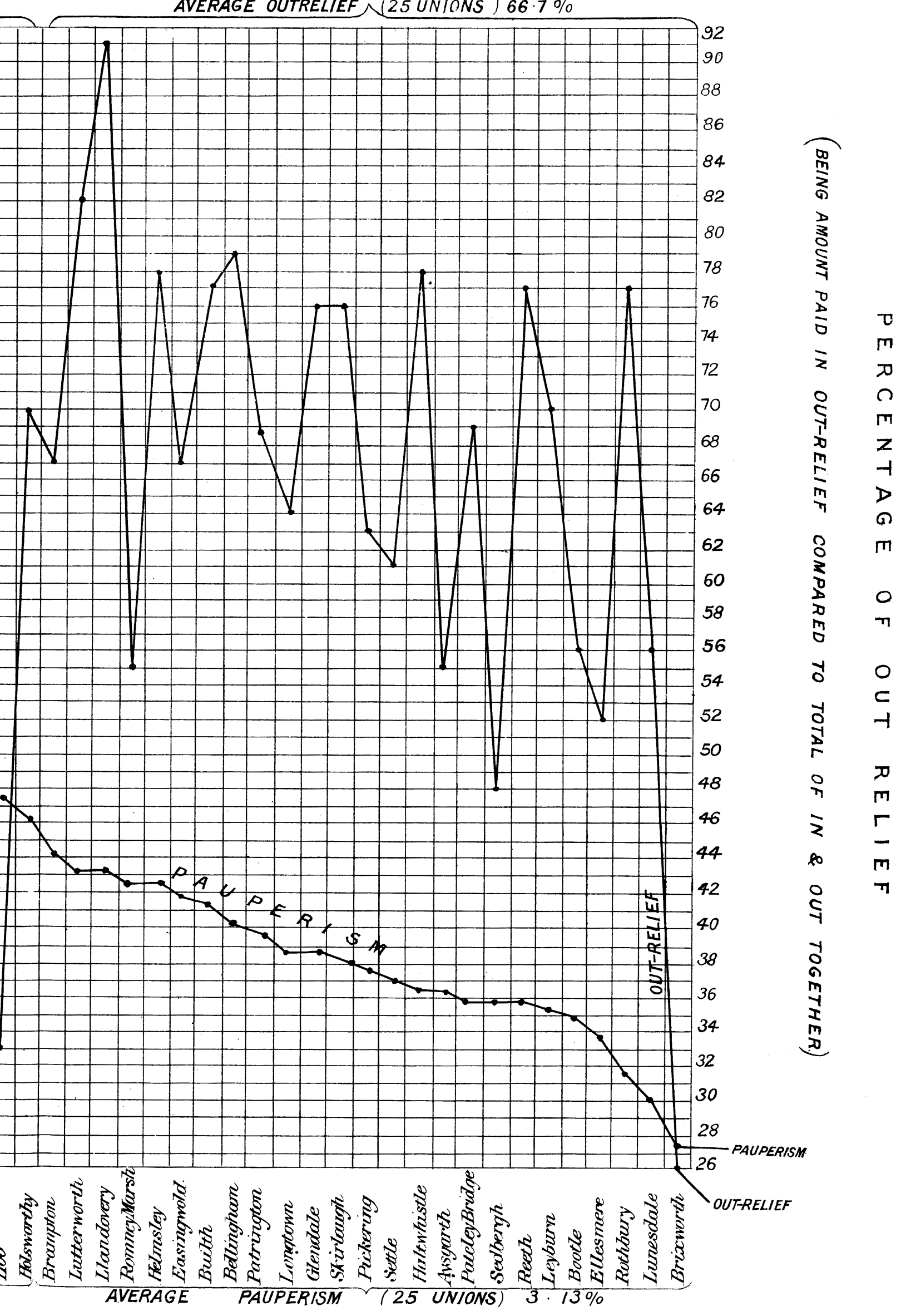


Pursuing the question further we find specimens of the lowest rates of pauperism with almost every proportion of out-relief, from $6 \frac{1}{2}$ per cent. (Atcham) to $85 \frac{1}{2}$ per cent. (Penzance). If we take unions with double the lowest rate of pauperism the same is true, the range for proportion of out-relief being from 15 per cent. (Milton) to 93 per cent. (Pontardawe), and if doubled again, that is with the highest rates of pauperism, the range is no less,

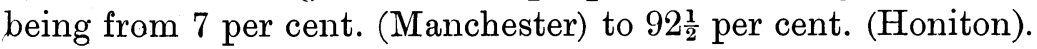

It may be true that where administration is lax a large proportion of out-relief will usually be given, but it is evident that the converse is not true. A large proportion of out-relief cannot be held necessarily to imply lax administration.

Mr. Yule in his tables uses figures which mix together the whole of the English unions whatever their character. I tried to avoid the dangers of this course by grouping, but I did not omit any union. The results are therefore as general as they can be, and not, I think, open to the charge which he makes of being an 'example of the fundamental mistake of founding general conclusions on particular instances.' Mr. Yule not only takes no account of difference in character, but also gives an equal value in his averages to every union whatever its size. In considering his criticism on my groups, I have followed the same plan, which though rather loose, is good enough for the purpose. It may also be good enough as he uses it, only the reader should be warned that the results are a very rough approximation of the true numerical facts.

Much more objectionable is the method he adopis in the text of his article of comparing the percentages of pauperism and outrelief respectively. In this he disregards altogether the relative values of the figures he uses. Thus he says, 'in group XVI. we have a drop of eleven in the out-relief corresponding to a drop of three in the pauperism,' but omits to observe that the eleven is obtained by comparing sixty-one and fifty, while the three results from comparing six and three. . Mr. Yule's sentence might leave the incautious reader under the impression that the drop in out-relief was nearly four times as great as that in pauperism, while in effect the drop in pauperism was nearly three times as great as that in out-relief.

With the one-day count, which Mr. Loch prefers and which Mr. Yule uses, the official figures undoubtedly do support the anti-out-relief policy. It is the strength of the case so presented, contrasted with its weakness when the year's count is taken, that forms the ground of my contention that a good deal of the 
reduction in pauperism shown by official figures is delusive as a test of social well-being. Improvement there has been, but it is mainly due to general prosperity rather than to any special policy of administration, and the grouping I have attempted seems to indicate that the general connection between refusal of out-relief and reduction of pauperism, so far as it is more than nominal, is mostly attributable to the widespread change from rural to urban conditions which has accompanied the general increase of national wealth. Out-relief can be given much more satisfactorily in rural than in urban districts, and as districts cease to be rural, so on the whole less out-relief is given. The theory thus is that increased wealth is the cause alike of $(a)$ decrease of pauperism, $(b)$ increased proportions of urban population, and (indirectly), (c) changed policy of administration. So far as this is true it is evident that $(\alpha)$ and $(c)$ do not bear to each other any actual causal relation. I do not wish to say that this is so entirely. The poor law reformers of our day have done much, though not so much as their enthusiasm for their own principles has led them to believe. On the other hand I am satisfied that the possible explanation of the facts here offered cannot be ignored with safety.

Moreover this explanation seems to me to be really borne out by the figures put forward by Mr. Yule and Mr. Loch themselves. It is impossible to regard the broad changes indicated in the comparative table for 1871 and 1891 given by Mr. Yule, without recognising that they are the outcome of very large influences, and it thus becomes difficult to connect them very closely with the operation of a change of policy which has admittedly been only partially applied. This impression is confirmed in detail by Mr. Loch's historical comparisons of pauperism from 1861 to 1891 in a number of unions ; for in no less than five of the nineteen unions taken, we find that decrease in the extent of pauperism continues in spite of an apparent reversal, or partial reversal, since 1881, of the anti-out-relief policy.

I may say in conclusion that in dealing with the statistics of pauperism, I have tried, it may be unsuccessfully, to avoid special pleading of any kind. I am at any rate no advocate of out-relief.

Charles Booth 